\title{
Are outcomes after total knee arthroplasty worsening over time? A time-trends study of activity limitation and pain outcomes
}

Jasvinder A Singh ${ }^{1,2,3^{*}}$ and David G Lewallen ${ }^{3}$

\begin{abstract}
Background: To examine whether function and pain outcomes of patients undergoing primary total knee arthroplasty (TKA) are changing over time.

Methods: The Mayo Clinic Total Joint Registry provided data for time-trends in preoperative and 2-year post-operative activity limitation and pain in primary TKA patients from 1993-2005. We used chi-square test and analysis for variance, as appropriate. Multivariable-adjusted analyses were done using logistic regression.

Results: In a cohort of 7,229 patients who underwent primary TKA during 1993-2005, mean age was 68.4 years (standard deviation (SD), 9.8), mean BMI was $31.1(\mathrm{SD}, 6.0)$ and 55\% were women. Crude estimates showed that preoperative moderate-severe overall limitation were seen in $7.3 \%$ fewer patients and preoperative moderate-severe pain in 2.7\% more patients in 2002-05, compared to 1992-95 ( $p<0.001$ for both). At 2-years, crude estimates indicated that compared to 1992-95, moderate-severe post-TKA overall limitation was seen in $4.7 \%$ more patients and moderate-severe post-TKA pain in 3.6\% more patients in 2002-05, both statistically significant ( $p \leq 0.018$ ) and clinically meaningful. In multivariable-adjusted analyses that adjusted for age, sex, anxiety, depression, Deyo-Charlson index, body mass index and preoperative pain/limitation, patients had worse outcomes 2-year post-TKA in 2002-2005 compared to 1993-95 with an odds ratio (95\% confidence interval (Cl); p-value) of 1.34 (95\% Cl: 1.02, 1.76, $p=0.037)$ for moderate-severe activity limitation and 1.79 (95\% Cl: $1.17,2.75, p=0.007)$ for moderate-severe pain.
\end{abstract}

Conclusion: Patient-reported function and pain outcomes after primary TKA have worsened over the study period 1993-95 to 2002-05. This time-trend is independent of changes in preoperative pain/limitation and certain patient characteristics.

Keywords: Total knee replacement, Time trends, Arthroplasty, Joint replacement, Pain, Function

\section{Background}

Total knee arthroplasty (TKA) is an extremely effective surgical treatment option for patients with end-stage refractory knee pain and associated functional disability. National Inpatient Sample (NIS) reported that 719,000 primary TKAs were performed in the U.S. in 2010 [1], consistent with the projected estimates from a populationbased study from the Olmsted County, Minnesota [2]. The estimated cost per TKA is approximately US \$24,200 [3],

\footnotetext{
* Correspondence: Jasvinder.md@gmail.com

'Medicine Service, Birmingham VA Medical Center, Birmingham, AL, England ${ }^{2}$ Department of Medicine at School of Medicine, and Division of Epidemiology at School of Public Health, University of Alabama, Birmingham, AL, England

Full list of author information is available at the end of the article
}

leading to an annual cost burden of 17.6 billion for TKA in the U.S in 2010. TKA volume has increased dramatically in the last few decades $[2,4]$ and is projected to reach 3.5 million TKAs annually by 2030 [5].

Many studies have focused on time-trends in utilization and specific in-hospital or immediate post-arthroplasty outcomes [6-9]. To our knowledge, there are no studies assessing whether there are any appreciable time-trends in post-operative PROs, i.e., if the PROs after TKA have improved, worsened or remained stable over time. This is a critical knowledge gap since TKA is an elective surgery that results in an impressive improvement in patientreported outcomes (PROs), including pain, function and quality of life in most patients [10]. A small but sizable 
proportion of patients have suboptimal pain (7-13\%) and function $(21-27 \%)$ outcomes post-TKA $[11,12]$. Even a $1 \%$ absolute increase means an additional 7,190 patients with suboptimal outcomes annually in the U.S. Sociodemographic and clinical characteristics of patients undergoing primary TKA cohort are changing rapidly with an increasing patient complexity over time in the U.S. [13]. If there is an evolution in PRO outcomes post-arthroplasty over time, we need to know and understand that from a policy maker, clinician and patient perspective. Therefore, the objectives of this study were to: (1) examine the time trends in preoperative PROs of functional outcome and pain in patients undergoing primary TKA; (2) assess whether the risk of suboptimal PROs post-TKA has changed over time; (3) assess whether the risk of improving or worsening PROs post-TKA over time is independent of the preoperative PROs; and (4) study how these timetrends in post-TKA outcomes impact patients in different categories of age, medical and psychological comorbidity and body mass index (BMI). We hypothesized that postTKA PROs would improve over time (hypothesis 1) and that most time-trends in improving PROs will be seen in the oldest, and in those with lower comorbidity and lower BMI (hypotheses 2-4).

\section{Methods}

We followed the recommendations from the Strengthening of Reporting in Observational studies in Epidemiology (STROBE) statement [14] to report study methods and results.

\section{Study setting, data source and study eligibility}

We included all patients from the Mayo Clinic Total Joint Registry who had undergone primary TKA between 19932005 and had completed a preoperative and/or 2-year postoperative pain and function questionnaire. The Mayo Clinic Total Joint Registry captures data on all patients who undergo knee, hip or other joint arthroplasty. For TKA, data are captured using the Mayo Knee Survey that has construct validity and reproducibility [15]. Mayo Knee Survey has questions related to pain and function, similar to the validated American Knee Society Scale [16], the most commonly used instrument in knee arthroplasty studies [17]. Several previous studies using the Mayo Knee Survey have been reported [12,18-20]. Mayo Clinic's Institutional Review Board approved this study.

\section{Predictor of interest}

The main predictor of interest was time-period, divided into 1993-1995, 1996-1998, 1999-2001 and 2002-2005. Given that our objective was to assess whether the pain and activity limitation had changed over time, we compared the prevalence of moderate-severe activity limitation and moderate-severe pain in the first period, i.e.,
1993-95 to the last period, i.e., 2002-05. Since the entire study period (13 years) was not an exact multiple of 3 , the last period consisted of 4-years.

\section{Outcomes of interest}

The main outcomes of interest were PROs, moderatesevere limitation of activities of daily living (ADL) and moderate-severe pain. For each of the 3 ADLs, walking, climbing stairs and getting out of a chair, patient responses were categorized into mild, moderate or severe limitation category, as previously $[12,19,20]$. Presence of $\geq 2$ ADLs with moderate or severe limitation was classified as overall moderate-severe activity limitation a priori (ref, all other categories), as previously [12,18-21]. We categorized responses to the pain question "Do you have pain in the knee in which the joint was replaced? (Please mark only one answer.)" into reference category no/mild pain (no pain, mild pain, pain with stairs only, pain with walking and stairs) or moderate-severe pain (moderate occasional, moderate continuous or severe pain), a priori, as previously $[18,20,22]$.

\section{Covariates}

We included several covariates (some potential confounders) that are associated with pain/function after TKA [23-26], namely: demographics (age, sex); BMI; preoperative ADL limitation; preoperative pain; and medical and psychological comorbidity. Preoperative ADL limitation and pain were assessed by questions similar to the 2year evaluation. Medical comorbidity was assessed using validated Deyo-Charlson index [27], a weighted scale of 17 comorbidities (including cardiac, pulmonary, renal, hepatic disease, diabetes, cancer, HIV and so on), expressed as a summative score where a higher score indicates more comorbidity. We examined psychological comorbidity by the presence of anxiety and depression at the time of surgery, based on the presence of International Classification of Diseases, ninth revision (ICD-9) codes in the Mayo Clinic electronic databases.

\section{Bias and sample size}

We included several known confounders of function and pain outcomes to reduce confounding bias, but the cohort study design raises the possibility of residual confounding bias. We accounted for non-response bias, an expected limitation of this study, by presenting the nonresponder characteristics and considering them in study interpretation. We did not perform any formal sample size calculations, since we anticipated $>6,000$ patients at both baseline and 2-year follow-up for our study, to provide adequate number of outcomes. Correlation of observations (bilateral TKA in a patient, simultaneous or sequential) was accounted for by using appropriate statistical methods. 


\section{Statistical analyses}

We compared crude rates of moderate-severe ADL limitation and pain across the four pre-specified time periods using chi-square tests. We used univariate and multivariable-adjusted logistic regression models, using a generalized estimating equations (GEE) approach, to assess the association between the most recent time period (i.e., 2002-05 compared to 1992-95) and moderate-severe ADL limitation/pain 2-years after primary TKA. This method adjusted for the correlation between observations on the same subject due to both knees having been replaced. As specified a priori, we compared the first and the last time-periods. The multivariable models were hierarchical and included the variables: (1) model 1: age and sex; (2) model 2: model 1+ medical comorbidity; (3) model 3: model $2+$ anxiety + depression; (4) model 4: model $3+$ medical comorbidity; (5) model 5: model $4+$ preoperative pain/ADL limitation (in the respective model); (5) model 6: model 5 + BMI.

Subgroup analyses were done by examining multi variable-adjusted model 5 in patient subpopulations of: (1) age, $<65$ vs. $\geq 65$; (2) psychological morbidity, defined as presence of anxiety and/or depression (none vs. any); (3) BMI, <30 vs. $\geq 30$; and (4) Deyo-Charlson index (zero vs. one or higher). Odds ratios (OR), 95\% confidence intervals (CI) and $\mathrm{p}$-values were calculated. A p-value $<0.05$ was considered statistically significant.

\section{Results}

Study cohort characteristics and crude rates of preoperative and 2-year postoperative functional limitation and pain

7,229 patients underwent primary TKA at our institution 1993-2005 and completed baseline preoperative assessments and 7,139 patients who completed 2-year assessments (Table 1). For the preoperative cohort, 55\% were women and $81 \%$ were older than 60 years. The mean (standard deviation) age, BMI and Deyo-Charlson comorbidity index for the study cohort were 68.4 (9.8), 31.1 (6.0) and 1.3 (2.0), respectively. Osteoarthritis was the underlying diagnosis in $94 \%$. Characteristics of 2 -year cohort were similar to the pre-operative cohort (Table 1).

\section{Preoperative}

Preoperative limitations in walking, climbing stairs and rising from chair showed significant time-trends $(\mathrm{p} \leq$ 0.007 ), with a lower proportion of patients with moderate or severe activity limitations in the more recent period compared to the earlier time-period, except for stair climbing (Table 2). Additional file 1 provides detailed assessment of limitations for ADLs and pain over time. Preoperative dependence on walking aids decreased significantly over time $(\mathrm{p}=0.025)$. Overall moderate-severe functional limitation, defined as two or more ADLs with moderate or severe limitations, were noted in $75.2 \%$,
Table 1 Characteristics of the primary TKA cohort preoperatively and at 2-year follow-up

\begin{tabular}{|c|c|c|}
\hline & $\begin{array}{l}\text { Preoperatively } \\
(n=7,229)\end{array}$ & $\begin{array}{c}\text { 2-year } \\
(n=7,139)\end{array}$ \\
\hline \multicolumn{3}{|l|}{ Gender } \\
\hline Females & $55 \%$ & $56 \%$ \\
\hline Males & $45 \%$ & $44 \%$ \\
\hline \multicolumn{3}{|l|}{ Age } \\
\hline$\leq 60$ & $19 \%$ & $18 \%$ \\
\hline$>60-70$ & $35 \%$ & $35 \%$ \\
\hline$>70-80$ & $38 \%$ & $38 \%$ \\
\hline$>80$ & $8 \%$ & $8 \%$ \\
\hline \multicolumn{3}{|l|}{ BMI } \\
\hline$<25$ & $13 \%$ & $13 \%$ \\
\hline $25.1-30$ & $35 \%$ & $35 \%$ \\
\hline $30.1-35$ & $30 \%$ & $29 \%$ \\
\hline $35.1-40$ & $14 \%$ & $14 \%$ \\
\hline$>40$ & $8 \%$ & $9 \%$ \\
\hline \multicolumn{3}{|l|}{ ASA class } \\
\hline$I-I I$ & $57 \%$ & $58 \%$ \\
\hline III-IV & $43 \%$ & $42 \%$ \\
\hline \multicolumn{3}{|l|}{ Diagnosis } \\
\hline Inflammatory arthritis & $4 \%$ & $4 \%$ \\
\hline Osteoarthritis & $94 \%$ & $94 \%$ \\
\hline Other & $2 \%$ & $2 \%$ \\
\hline \multicolumn{3}{|l|}{ Cement fixation } \\
\hline Uncemented & $2 \%$ & $2 \%$ \\
\hline Cemented/hybrid & $98 \%$ & $98 \%$ \\
\hline
\end{tabular}

BMI, Body mass index.

31 missing for BMI, 30 missing for ASA score.

$72.1 \%, 65.4 \%$ and $67.9 \%$ patients in the four time-periods, indicating a statistically significant decline in preoperative ADL limitations over time $(\mathrm{p}<0.001$; Table 2$)$. The reduction in overall moderate-severe preoperative ADL limitation was attributable mainly to reduction in limitation in getting out of chair (18.4\% fewer) and walking ( $5.7 \%$ fewer). The proportion of patients with moderate/ severe preoperative pain increased from $64.3 \%$ in $1993-$ 95 to $67 \%$ in $2002-05$ with a significant time-trend ( $\mathrm{p}<$ 0.001; Table 2).

\section{Postoperative}

Compared to 1992-95, moderate-severe post-TKA overall ADL limitation was seen in $4.7 \%$ more patients and moderate-severe post-TKA pain in $3.6 \%$ more patients in 2002-05, both statistically significant ( $\mathrm{p} \leq 0.018$; Table 3 ). Compared to $1992-95,8.6 \%$ and 5.9\% more patients had moderate or severe limitations in walking and stairs postTKA during 2002-05, and 1.3\% fewer had moderate-severe 
Table 2 Time-trends in moderate-severe preoperative pain and functional limitation

\begin{tabular}{|c|c|c|c|c|c|c|}
\hline & $\begin{array}{c}1993-1995 \\
(n \sim 1,510)^{*} \\
\end{array}$ & $\begin{array}{c}1996-1998 \\
(\mathbf{n} \sim 1,646)^{*}\end{array}$ & $\begin{array}{l}1999-2001 \\
(\mathbf{n} \sim 1539)^{*}\end{array}$ & $\begin{array}{l}2002-2005 \\
(\mathrm{n} \sim 2,480)^{*}\end{array}$ & $\begin{array}{l}\text { Absolute Difference } \\
\text { (period } 1 \text {-period 4) }\end{array}$ & $\begin{array}{l}\mathrm{p} \text {-value for } \\
\text { time-trend }\end{array}$ \\
\hline Preoperative walking limitations & & & & & & $<0.001$ \\
\hline None/Mild & $25.7 \%$ & $25.9 \%$ & $32.2 \%$ & $31.4 \%$ & & \\
\hline Moderate/Severe & $74.3 \%$ & $74.1 \%$ & $67.8 \%$ & $68.6 \%$ & $-5.7 \%$ & \\
\hline Preoperative stairs limitations & & & & & & 0.007 \\
\hline None/Mild & $14.4 \%$ & $15.5 \%$ & $16.7 \%$ & $12.7 \%$ & & \\
\hline Moderate/Severe & $85.6 \%$ & $84.5 \%$ & $83.3 \%$ & $87.3 \%$ & $+1.7 \%$ & \\
\hline Preoperative chair limitations & & & & & & $<0.001$ \\
\hline None/Mild & $58.4 \%$ & $65.3 \%$ & $71.2 \%$ & $76.8 \%$ & & \\
\hline Moderate/Severe & $41.6 \%$ & $34.7 \%$ & $28.8 \%$ & $23.2 \%$ & $-18.4 \%$ & \\
\hline Preoperative walking aids & & & & & & 0.025 \\
\hline No/mild dependence & $70.9 \%$ & $71.9 \%$ & $72.0 \%$ & $75.3 \%$ & & \\
\hline Moderate dependence & $18.3 \%$ & $16.4 \%$ & $16.7 \%$ & $15.4 \%$ & $-2.9 \%$ & \\
\hline Complete dependence or unable to walk & $10.8 \%$ & $11.7 \%$ & $11.3 \%$ & $9.3 \%$ & $-1.5 \%$ & \\
\hline Preoperative overall ADL limitations & & & & & & $<0.001$ \\
\hline None/Mild & $24.8 \%$ & $27.9 \%$ & $34.6 \%$ & $32.1 \%$ & & \\
\hline Moderate/Severe & $75.2 \%$ & $72.1 \%$ & $65.4 \%$ & $67.9 \%$ & $-7.3 \%$ & \\
\hline Preoperative pain & & & & & & $<0.001$ \\
\hline None/Mild/Stairs/Stairs and walking & $35.7 \%$ & $39.4 \%$ & $41.8 \%$ & $33.0 \%$ & & \\
\hline Moderate/Severe & $64.3 \%$ & $60.6 \%$ & $58.2 \%$ & $67.0 \%$ & $+2.7 \%$ & \\
\hline
\end{tabular}

ADL, activities of daily living.

*Missingness ranged from $1 \%$ to $3 \%$ for various variables, since not all the patients answered each question on the survey.

limitations in getting out of chair (Table 3). The proportion of patients with moderate/severe post-TKA pain increased from $5.0 \%$ in $1993-95$ to $8.6 \%$ in $2002-05$ with a significant time-trend $(\mathrm{p}<0.001$; Table 2$)$, an almost doubling of the incidence.

Did post-TKA overall moderate-severe ADL limitation and moderate-severe pain decrease over time? (Hypothesis 1) Unadjusted analyses showed that the odds of moderatesevere ADL limitation and moderate-severe pain at 2year postoperative were significantly higher in 2002-05 compared to 1992-95 (Table 4). Multivariable hierarchical models showed that odds were minimally attenuated after adjustment, contrary to our hypothesis that PROs would improve over time (Table 4). Adjustment for preoperative pain/limitation, arguably the most important variable, led to higher odds ratios of 1.34-1.40 for moderate-severe ADL limitation and 1.79-1.80 for moderate-severe pain.

Did time-trends in post-TKA outcomes differ by age, comorbidity and BMI? (Hypotheses 2-4)

Subgroup analyses were performed by age, psychological comorbidity, BMI and Deyo-Charlson comorbidity. The increased odds of moderate-severe ADL limitation and moderate-severe pain in 2002-05 compared to 1992-95 persisted in patients 65 years and older, but not in patients younger than 65 years (Table 5). Patients without psychological comorbidity had significantly higher odds of moderate-severe ADL limitation and moderate-severe pain in 2002-05 compared to 1992-95 (Table 5), but not patients with psychological comorbidity. The increased odds of moderate-severe pain in 2002-05 compared to 1992-95 were evident for patients with Deyo-Charlson index of 1 or higher or $\mathrm{BMI} \geq 30$, but not in those with Deyo-Charlson index of zero or BMI $<30$ (Table 5).

\section{Discussion}

We found a significant increase in the odds of suboptimal post-primary TKA function and pain outcomes from 199295 to 2002-05. In contrast, preoperative moderate-severe ADL limitation decreased and preoperative moderatesevere pain minimally increased from 1993-95 to 2002-05. The adjusted odds of 2-year post-TKA moderate-severe ADL limitation increased by $34 \%$ over the study period, while the odds of 2-year post-TKA moderate-severe pain increased by $79 \%$. The absolute increases in postTKA overall moderate-severe ADL and pain limitations between the first and last time-periods were 4.7\% (19\% vs. $23.7 \%$ ) and $3.6 \%$ (5\% vs. $8.6 \%$ ), statistically significant and clinically meaningful. These findings add to the current knowledge in post-arthroplasty PROs. We are 
Table 3 Time-trends in 2-year post-primary TKA pain and functional limitation outcomes

\begin{tabular}{|c|c|c|c|c|c|c|}
\hline & $\begin{array}{c}1993-1995 \\
(n \sim 1,510)^{*}\end{array}$ & $\begin{array}{c}1996-1998 \\
(\mathrm{n} \sim 1,646)^{*}\end{array}$ & $\begin{array}{l}1999-2001 \\
(\mathrm{n} \sim 1539)^{*}\end{array}$ & $\begin{array}{l}2002-2005 \\
(\mathrm{n} \sim 2,480)^{*}\end{array}$ & $\begin{array}{l}\text { Absolute Difference } \\
\text { (period } 1 \text {-period 4) }\end{array}$ & $\begin{array}{l}\mathrm{p} \text {-value for } \\
\text { time-trend }\end{array}$ \\
\hline 2-year walking limitations & & & & & & $<0.001$ \\
\hline None/Mild & $80.4 \%$ & $75.0 \%$ & $72.9 \%$ & $71.8 \%$ & & \\
\hline \multirow[t]{2}{*}{ Moderate/Severe } & $19.6 \%$ & $25.0 \%$ & $27.1 \%$ & $28.2 \%$ & $+8.6 \%$ & \\
\hline & & & & & & 0.001 \\
\hline \multicolumn{7}{|l|}{ 2-year stairs limitations } \\
\hline None/Mild & $62.6 \%$ & $59.5 \%$ & $62.0 \%$ & $56.6 \%$ & & \\
\hline Moderate/Severe & $37.4 \%$ & $40.5 \%$ & $38.0 \%$ & $43.3 \%$ & $+5.9 \%$ & \\
\hline 2-year chair limitations & & & & & & 0.57 \\
\hline None/Mild & $91.0 \%$ & $91.7 \%$ & $92.1 \%$ & $92.3 \%$ & & \\
\hline Moderate/Severe & $9.0 \%$ & $8.3 \%$ & $7.9 \%$ & $7.7 \%$ & $-1.3 \%$ & \\
\hline 2-year walking aids & & & & & & 0.14 \\
\hline No/mild dependence** & $88.0 \%$ & $88.3 \%$ & $88.9 \%$ & $88.8 \%$ & & \\
\hline Moderate dependence & $4.5 \%$ & $5.8 \%$ & $5.4 \%$ & $4.9 \%$ & $+0.4 \%$ & \\
\hline Complete dependence or unable to walk & $7.5 \%$ & $5.9 \%$ & $5.7 \%$ & $6.2 \%$ & $-0.7 \%$ & \\
\hline 2-year overall ADL limitations & & & & & & 0.018 \\
\hline None/Mild & $81.0 \%$ & $77.3 \%$ & $77.7 \%$ & $76.3 \%$ & & \\
\hline Moderate/Severe & $19.0 \%$ & $22.7 \%$ & $22.3 \%$ & $23.7 \%$ & $+4.7 \%$ & \\
\hline 2-year TKA pain & & & & & & $<0.001$ \\
\hline None/Mild/Stairs/Stairs and walking & $95.0 \%$ & $93.3 \%$ & $93.5 \%$ & $91.4 \%$ & & \\
\hline Moderate/Severe & $5.0 \%$ & $6.7 \%$ & $6.5 \%$ & $8.6 \%$ & $+3.6 \%$ & \\
\hline
\end{tabular}

*Missingness ranged from $1 \%$ to $3 \%$ for various variables, since not all the patients answered each question on the survey.

**No/mild dependence, no supports or cane long walk.

Table 4 Univariate and Multivariable-adjusted odds of post-TKA moderate-severe ADL limitation and moderate-severe pain in 2002-05 compared to 1993-1995

\begin{tabular}{|c|c|c|}
\hline & \multicolumn{2}{|c|}{ Odds of outcome in $2002-05$ compared to $1993-1995$} \\
\hline & Odds ratio $(95 \% \mathrm{Cl})$ & p-value \\
\hline \multicolumn{3}{|l|}{ 2-year Overall Moderate-severe ADL limitation } \\
\hline Unadjusted & $1.32(1.09,1.61)$ & 0.005 \\
\hline Age, sex adjusted & $1.31(1.06,1.60)$ & 0.011 \\
\hline Age, sex, comorbidity adjusted & $1.24(1.01,1.52)$ & 0.044 \\
\hline Age, sex, anxiety, depression adjusted & $1.21(0.98,1.49)$ & 0.071 \\
\hline Age, sex, comorbidity, anxiety, depression adjusted & $1.17(0.95,1.44)$ & 0.146 \\
\hline Age, sex, comorbidity, anxiety, depression, preoperative ADL limitation adjusted & $1.40(1.07,1.83)$ & 0.015 \\
\hline Age, sex, comorbidity, anxiety, depression, preoperative ADL limitation, BMI adjusted & $1.34(1.02,1.76)$ & 0.037 \\
\hline \multicolumn{3}{|l|}{ 2-year Moderate-Severe Pain } \\
\hline Unadjusted & $1.79(1.30,2.45)$ & $<0.001$ \\
\hline Age, sex adjusted & $1.74(1.26,2.39)$ & 0.001 \\
\hline Age, sex, comorbidity adjusted & $1.72(1.25,2.37)$ & 0.001 \\
\hline Age, sex, comorbidity, anxiety, depression adjusted & $1.65(1.19,2.28)$ & 0.002 \\
\hline Age, sex, comorbidity, anxiety, depression, preoperative pain adjusted & $1.80(1.17,2.75)$ & 0.007 \\
\hline Age, sex, comorbidity, anxiety, depression, preoperative pain, BMI adjusted & $1.79(1.17,2.75)$ & 0.007 \\
\hline
\end{tabular}

Bold indicates significant odds ratios. 
Table 5 Subgroup Analyses of the time-trends in post-TKA moderate-severe ADL limitation and moderate-severe pain in 2002-05 compared to 1993-1995 by important patient characteristics

\begin{tabular}{|c|c|c|c|c|}
\hline & Odds ratio $(95 \% \mathrm{Cl})$ & P-value & Odds ratio $(95 \% \mathrm{Cl})$ & P-value \\
\hline & \multicolumn{2}{|c|}{ Age $<65$} & \multicolumn{2}{|c|}{ Age $\geq 65$} \\
\hline 2-yr Overall Moderate-severe ADL limitation ${ }^{1}$ & $0.70(0.41,6.05)$ & 0.19 & $1.43(1.06,1.95)$ & 0.021 \\
\hline \multirow[t]{2}{*}{ 2-yr Mod-Severe Pain ${ }^{1}$} & $1.63(0.77,3.47)$ & 0.20 & $1.81(1.07,3.07)$ & 0.026 \\
\hline & \multicolumn{2}{|c|}{ No Psychological morbidity } & \multicolumn{2}{|c|}{ Psychological morbidity } \\
\hline 2-yr Overall Moderate-severe ADL limitation ${ }^{2}$ & $1.50(1.12,2.00)$ & 0.006 & $0.74(0.29,1.93)$ & 0.54 \\
\hline \multirow[t]{2}{*}{ 2-yr Mod-Severe Pain ${ }^{2}$} & $1.61(1.02,2.53)$ & 0.039 & $3.82(0.87,16.7)$ & 0.076 \\
\hline & \multicolumn{2}{|c|}{ BMI $<30$} & \multicolumn{2}{|c|}{$\mathrm{BMI} \geq 30$} \\
\hline 2-yr Overall Moderate-severe ADL limitation ${ }^{3}$ & $1.11(0.75,1.65)$ & 0.60 & $1.36(0.95,1.95)$ & 0.094 \\
\hline \multirow[t]{2}{*}{ 2-yr Mod-Severe Pain 3} & $1.44(0.82,2.53)$ & 0.20 & $2.19(1.11,4.31)$ & 0.023 \\
\hline & \multicolumn{2}{|c|}{ Deyo-Charlson index 0} & \multicolumn{2}{|c|}{ Deyo-Charlson index 1 or higher } \\
\hline 2-yr Overall Moderate-severe ADL limitation ${ }^{4}$ & $1.48(1.00,2.20)$ & 0.053 & $1.09(0.76,1.56)$ & 0.62 \\
\hline 2-yr Mod-Severe Pain ${ }^{4}$ & $1.56(0.88,2.74)$ & 0.125 & $2.16(1.12,4.15)$ & 0.021 \\
\hline
\end{tabular}

Psychological comorbidity was defined as the presence of anxiety, depression or both.

1 adjusted for age, sex, comorbidity, anxiety, depression, BMI, preoperative pain/function

${ }^{2}$ adjusted for age, sex, comorbidity, BMI, preoperative pain/function (not adjusted for anxiety or depression, since the groups were stratified by its presence).

${ }^{3}$ adjusted for age, sex, comorbidity, anxiety, depression, BMI, preoperative pain/function (not adjusted for BMI, since the groups were stratified by BMI).

${ }^{4}$ adjusted for age, sex, anxiety, depression, BMI, preoperative pain/function (not adjusted for comorbidity, since the groups were stratified by Deyo-Charlson comorbidity score).

Bold indicates significant odds ratios.

not aware of any other study of time-trends in PROs after primary TKA.

Our study addressed our first hypothesis, i.e., timetrends in post-TKA function and pain outcomes, which contrary to our expectation, actually worsened over time. Medical [25,28,29] and psychological comorbidity [30-32] and obesity [33], factors associated with more complications and/or worse PROs after primary TKA, have worsened over time $[6,13]$ in patients undergoing primary TKA. Interestingly, adjusting for preoperative medical and psychological comorbidity, age, BMI and other confounders (sex and preoperative pain and ADL limitation) had no/ minimal effect on time-trends in post-TKA moderatesevere ADL limitation or pain. This implies that increasing comorbidity, BMI, preoperative pain and ADL limitation over time do not explain the time-related worsening in post-TKA ADL limitations and pain outcomes. An impressive finding was an almost doubling of moderate-severe pain from $5 \%$ to $8.5 \%$ over the 13 -year study period. This increase in the proportion of patients with suboptimal pain outcomes 2-year post-primary TKA over 13-years was an unexpected finding that needs further study. This $8.5 \%$ annual rate translates into 61,115 moderate-severely painful TKAs in 2010 alone, which represents a significant public health and patient burden.

So, why in the face of lower proportion of patients with moderate-severe ADL limitation (albeit higher proportion with moderate-severe pain) preoperatively, are postoperative pain and function outcomes worsening over time? Since our final models were adjusted for preoperative status and various other important factors, the time- trends in post-operative pain and function are in fact independent of changes in preoperative pain and function, respectively. We think that the increase in odds of moderate-severe ADL limitation over time may be related to shorter inpatient stay and a lower proportion discharged to home over time [6], both of which may lead to more suboptimal recovery; on the other hand, recent improvements in pre- and post-operative rehabilitation programs might be expected to improve post-TKA functional outcomes [34]. Potential causes for worsening pain outcomes over time may be the increasing prevalence of osteoarthritis over time [35,36], which may lead to higher likelihood of other lower extremity joint involvement or the spine, which may contribute to persistent index TKA pain due to referred pain from another osteoarthritic joint (i.e. hip or back) or due to interference with optimal physical therapy and rehabilitation post-TKA [37,38]. The increase in odds of 1.34 in moderate-severe ADL limitation was more modest as compared to the increase in odds of moderate-severe pain (OR, 1.77).

Future studies need to examine whether other factors such as psychological distress (e.g. post-traumatic stress disorder), coping strategies, family support, pain medication use in the postoperative period and/or type of rehabilitation, can explain the worsening pain and function outcomes after primary TKA over time. We used a diagnostic code, not a questionnaire, for depression/anxiety and therefore we may have missed subclinical or undiagnosed disease. Severity of depression or anxiety was not measured in our study, which may also contribute to worsening of persistent pain/functional limitation post-TKA. 
Over time, TKA has been made available to a wider patient population, some of whom may have been excluded previously, due to an unfavorable patient profile, not likely to benefit optimally from TKA. Worsening in other patient characteristics (proportion with fibromyalgia, catastrophizing etc.) over time not measured in our study may also be contributing to worsening outcomes over time.

Our subgroup analyses provided important insights. We hypothesized that post-TKA pain and function outcomes would improve over time in the oldest, and in those with lower comorbidity and lower BMI. We noted worse pain and function outcomes in 2002-05 compared to $1993-95$ in the patients 65 years and older and those without psychological comorbidity. This was contrary to our expectations, since we hypothesized that patients with psychological comorbidity and those in the younger age group (who also have worse psychological comorbidity) might be the ones at highest risk of worsening PRO outcomes over time. These associations were also independent of sex, preoperative pain/function, BMI and preoperative comorbidity. To our knowledge, this is the first study to report these findings. Another novel finding was that pain outcomes in the 2002-05 were worse compared to 1993-95 in patients with Deyo-Charlson index of one or more or BMI $\geq 30$. Thus, our study identified specific patient populations who demonstrate worsening PRO outcomes post-TKA. Patients with these characteristics should be the focus of the future studies to investigate the reasons for worsening PROs over time and design strategies to improve PROs.

Study findings must be interpreted considering the study limitations. Non-response may have biased our results. Non-responders to 2-year survey were more likely than responders to have slightly higher co-morbidity, higher ASA class, greater distance to the medical center and were younger. However, the direction of bias is unclear since it's not known how the patient characteristics associated with non-response might have impacted these time-trends. This is single center study and generalizability to other settings may be challenging. The similarity of our cohort to other published cohorts [39-41] as well as a national U. S. sample [7], supports the representativeness of our sample. Use of diagnostic codes for medical and surgical comorbidity may have led to under-recognition of these conditions, which would bias study results towards null, making our estimates conservative. Deyo-Charlson index that uses diagnostic codes is a validated comorbidity measure [27] and the prevalence of depression using codes is similar to the $9-15 \%$ reported in studies using validated instruments for depression [42-44]. The use of multimodal pain protocols, in- and outpatient rehabilitation programs, practice of earlier joint mobilization as well as prosthesis and surgery techniques may have evolved over time and could have positively or negatively impacted pain outcomes, especially in the last few years. We could not explore these trends in the more recent as well as assess the contribution of these potential secular trends due to limited resources and lack of availability of these data in our databases. This should be explored in future studies. Our study had several strengths. We used a large sample from a Total Joint Registry, and adjusted analyses for potential confounders and covariates of pain and functional outcomes.

\section{Conclusion}

In conclusion, we found that post-TKA PRO outcomes 2 years after primary TKA had worsened from 1993-95 to 2002-05. In particular, the odds of moderate-severe ADL limitation and pain were higher in the most recent timeperiod. Time-related worsening of pain and ADL outcomes was independent of pre-operative ADL limitation and pain and other factors associated with post-TKA pain and functional limitation. The increase in odds was noted in particular in patients with older age, no psychological morbidity, obesity and higher medical comorbidity. Future studies are needed to identify the reasons for worsening pain and functional outcomes in general and in these groups of patients so that interventions can be targeted for improving post-arthroplasty outcomes.

\section{IRB approval}

The Mayo Clinic Institutional Review Board approved this study and all investigations were conducted in conformity with ethical principles of research.

\section{Additional file}

Additional file 1: Time trends in unadjusted rates of preoperative pain and activity limitation.

\section{Abbreviations}

TKA: Total knee arthroplasty; BMI: Body mass index; PRO: Patient-reported outcomes; ADL: Activities of daily living.

\section{Competing interests}

There are no financial conflicts related directly to this study. J.A.S. has received research and travel grants from Takeda and Savient; and consultant fees from Savient, Takeda, Regeneron AND Allergan, and Novartis. D.G.L. has received royalties/speaker fees from Zimmer, Orthosonic and Osteotech, has been a paid consultant and owns stock in Pipeline Biomedical; his institution has received research funds from DePuy, Stryker, Biomet and Zimmer.

\section{Authors' contributions}

JAS designed the study, developed the protocol and obtained IRB approval, conducted and interpreted the analyses, wrote the first draft of the

manuscript and revised it and made the decision to submit it. DGL reviewed the protocol and suggested modifications, interpreted the analyses, critically revised the manuscript and approved the final version of the manuscript for submission.

\section{Grant support}

JAS is supported by grants from the Agency for Health Quality and Research Center for Education and Research on Therapeutics (AHRQ CERTs) U19 HS021110, National Institute of Arthritis, Musculoskeletal and Skin Diseases 
(NIAMS) P50 AR060772 and U34 AR062891, National Institute of Aging (NIA) U01 AG018947, and National Cancer Institute (NCI) U10 CA149950, and research contract CE-1304-6631 from Patient Centered Outcomes Research Institute (PCORI). JAS is also supported by the resources and the use of facilities at the VA Medical Center at Birmingham, Alabama, USA.

\section{Role of the funding sources}

The funding sources played no role in development of the study protocol, data analyses or interpretation, preparation of the manuscript or the decision to submit it.

\section{Author details}

${ }^{1}$ Medicine Service, Birmingham VA Medical Center, Birmingham, AL, England. ${ }^{2}$ Department of Medicine at School of Medicine, and Division of Epidemiology at School of Public Health, University of Alabama, Birmingham, AL, England. ${ }^{3}$ Department of Orthopedic Surgery, Mayo Clinic College of Medicine, Rochester, MN, USA.

Received: 16 June 2014 Accepted: 10 December 2014

Published: 17 December 2014

\section{References}

1. Healthcare Cost and Utilization Project. Most Frequent Procedures Performed in U.S. Hospitals. 2010. http://www.hcup-us.ahrq.gov/reports/statbriefs/sb149.pdf.

2. Singh JA, Vessely MB, Harmsen WS, Schleck CD, Melton $\amalg$ 3rd, Kurland RL, Berry DJ: A population-based study of trends in the use of total hip and total knee arthroplasty, 1969-2008. Mayo Clin Proc 2010, 85(10):898-904.

3. Cropp I: Why it costs $\$ 24,200$ for a knee replacement. In Washington Post. Washington, D.C: 2011. http://www.washingtonpost.com/wp-dyn/content/ article/2011/02/26/AR2011022603474.html.

4. Kurtz S, Mowat F, Ong K, Chan N, Lau E, Halpern M: Prevalence of primary and revision total hip and knee arthroplasty in the United States from 1990 through 2002. J Bone Joint Surg Am 2005, 87(7):1487-1497.

5. Kurtz S, Ong K, Lau E, Mowat F, Halpern M: Projections of primary and revision hip and knee arthroplasty in the United States from 2005 to 2030. J Bone Joint Surg Am 2007, 89(4):780-785.

6. Cram P, Lu X, Kates SL, Singh JA, Li Y, Wolf BR: Total knee arthroplasty volume, utilization, and outcomes among Medicare beneficiaries, 19912010. JAMA 2012, 308(12):1227-1236.

7. Kirksey M, Chiu YL, Ma Y, Della Valle AG, Poultsides L, Gerner P, Memtsoudis SG Trends in in-hospital major morbidity and mortality after total joint arthroplasty: United States 1998-2008. Anesth Analg 2012, 115(2):321-327.

8. Seah WW, Singh G, Yang KY, Yeo SJ, Lo NN, Seow KH: Thirty-day mortality and morbidity after total knee arthroplasty. Ann Acad Med Singapore 2007, 36(12):1010-1012.

9. Skramm I, Saltyte Benth J, Bukholm G: Decreasing time trend in SSI incidence for orthopaedic procedures: surveillance matters! J Hosp Infect 2012, 82(4):243-247.

10. Ethgen O, Bruyere O, Richy F, Dardennes C, Reginster JY: Health-related quality of life in total hip and total knee arthroplasty. A qualitative and systematic review of the literature. J Bone Joint Surg Am 2004, 86-A(5):963-974.

11. Brander VA, Stulberg SD, Adams AD, Harden RN, Bruehl S, Stanos SP, Houle T: Predicting total knee replacement pain: a prospective, observational study. Clin Orthop Relat Res 2003, 416:27-36.

12. Singh $J A, O^{\prime} B y r n e ~ M$, Harmsen $S$, Lewallen D: Predictors of moderatesevere functional limitation after primary Total Knee Arthroplasty (TKA): 4701 TKAs at 2-years and 2935 TKAs at 5-years. Osteoarthritis Cartilage 2010, 18(4):515-521.

13. Singh JA, Lewallen DG: Time trends in the Characteristics of Patients Undergoing Primary Total Knee Arthroplasty. Arthritis Care Res (Hoboken) 2014. In press.

14. STROBE Statement. Strengthening the reporting of observational studies in epidemiology. Link. http://www.strobe-statement.org/index.php?id=availablechecklists.

15. McGrory BJ, Morrey BF, Rand JA, Ilstrup DM: Correlation of patient questionnaire responses and physician history in grading clinical outcome following hip and knee arthroplasty. A prospective study of 201 joint arthroplasties. J Arthroplasty 1996, 11(1):47-57.

16. Insall JN, Dorr LD, Scott RD, Scott WN: Rationale of the Knee Society clinical rating system. Clin Orthop Relat Res 1989, 248:13-14.
17. Riddle DL, Stratford PW, Bowman DH: Findings of extensive variation in the types of outcome measures used in hip and knee replacement clinical trials: a systematic review. Arthritis Rheum 2008, 59(6):876-883.

18. Singh JA, Gabriel SE, Lewallen DG: Higher body mass index is not associated with worse pain outcomes after primary or revision total knee arthroplasty. J Arthroplasty 2011, 26(3):366-374. e361.

19. Singh JA, O'Byrne MM, Harmsen WS, Lewallen DG: Predictors of moderatesevere functional limitation 2 and 5 years after revision total knee arthroplasty. J Arthroplasty 2010, 25(7):1091-1095. 1095 e1091-1094.

20. Singh JA, O'Byrne MM, Colligan RC, Lewallen DG: Pessimistic explanatory style: a psychological risk factor for poor pain and functional outcomes two years after knee replacement. J Bone Joint Surg Br 2010, 92(6):799-806.

21. Singh JA, Gabriel S, Lewallen D: The impact of gender, age, and preoperative pain severity on pain after TKA. Clin Orthop Relat Res 2008, 466(11):2717-2723.

22. Singh JA, Lewallen DG: Predictors of use of pain medications for persistent knee pain after primary Total Knee Arthroplasty: a cohort study using an institutional joint registry. Arthritis Res Ther 2012, 14(6):R248.

23. Fisher DA, Dierckman B, Watts MR, Davis K: Looks good but feels bad: factors that contribute to poor results after total knee arthroplasty. J Arthroplasty 2007, 22(6 Suppl 2):39-42.

24. Jones CA, Voaklander DC, Suarez-Alma ME: Determinants of function after total knee arthroplasty. Phys Ther 2003, 83(8):696-706.

25. Lingard EA, Katz JN, Wright EA, Sledge CB: Predicting the outcome of total knee arthroplasty. J Bone Joint Surg Am 2004, 86-A(10):2179-2186.

26. Rajgopal V, Bourne RB, Chesworth BM, MacDonald SJ, McCalden RW, Rorabeck $\mathrm{CH}$ : The impact of morbid obesity on patient outcomes after total knee arthroplasty. J Arthroplasty 2008, 23(6):795-800.

27. Deyo RA, Cherkin DC, Ciol MA: Adapting a clinical comorbidity index for use with ICD-9-CM administrative databases. J Clin Epidemiol 1992, 45(6):613-619.

28. Jones CA, Voaklander DC, Johnston DW, Suarez-Almazor ME: The effect of age on pain, function, and quality of life after total hip and knee arthroplasty. Arch Intern Med 2001, 161(3):454-460.

29. Wasielewski RC, Weed H, Prezioso C, Nicholson C, Puri RD: Patient comorbidity: relationship to outcomes of total knee arthroplasty. Clin Orthop Relat Res 1998, 356:85-92.

30. Lopez-Olivo MA, Landon GC, Siff SJ, Edelstein D, Pak C, Kallen MA, Stanley M, Zhang H, Robinson KC, Suarez-Almazor ME: Psychosocial determinants of outcomes in knee replacement. Ann Rheum Dis 2011, 70(10):1775-1781.

31. Brander V, Gondek S, Martin E, Stulberg SD: Pain and depression influence outcome 5 years after knee replacement surgery. Clin Orthop Relat Res 2007, 464:21-26.

32. Vissers MM, Bussmann JB, Verhaar JA, Busschbach JJ, Bierma-Zeinstra SM, Reijman M: Psychological factors affecting the outcome of total hip and knee arthroplasty: a systematic review. Semin Arthritis Rheum 2012, 41(4):576-588.

33. Kerkhoffs GM, Servien E, Dunn W, Dahm D, Bramer JA, Haverkamp D: The influence of obesity on the complication rate and outcome of total knee arthroplasty: a meta-analysis and systematic literature review. $J$ Bone Joint Surg Am 2012, 94(20):1839-1844.

34. Petterson SC, Mizner RL, Stevens JE, Raisis L, Bodenstab A, Newcomb W, Snyder-Mackler L: Improved function from progressive strengthening interventions after total knee arthroplasty: a randomized clinical trial with an imbedded prospective cohort. Arthritis Rheum 2009, 61(2):174-183.

35. Haugen IK, Englund M, Aliabadi P, Niu J, Clancy M, Kvien TK, Felson DT: Prevalence, incidence and progression of hand osteoarthritis in the general population: the Framingham Osteoarthritis Study. Ann Rheum Dis 2011, 70(9):1581-1586.

36. Kopec JA, Rahman MM, Sayre EC, Cibere J, Flanagan WM, Aghajanian J, Anis AH, Jordan JM, Badley EM: Trends in physician-diagnosed osteoarthritis incidence in an administrative database in British Columbia, Canada, 1996-1997 through 2003-2004. Arthritis Rheum 2008, 59(7):929-934.

37. Maxwell J, Niu J, Singh JA, Nevitt MC, Law LF, Felson D: The influence of the contralateral knee prior to knee arthroplasty on post-arthroplasty function: the multicenter osteoarthritis study. J Bone Joint Surg Am 2013, 95(11):989-993.

38. Singh JA, Lewallen DG: Ipsilateral lower extremity joint involvement increases the risk of poor pain and function outcomes after hip or knee arthroplasty. BMC Med 2013, 11:144. 
39. Kamath AF, Horneff JG, Gaffney V, Israelite CL, Nelson CL: Ethnic and gender differences in the functional disparities after primary total knee arthroplasty. Clin Orthop Relat Res 2010, 468(12):3355-3361.

40. Zeni JA Jr, Snyder-Mackler L: Most patients gain weight in the 2 years after total knee arthroplasty: comparison to a healthy control group. Osteoarthritis Cartilage 2010, 18(4):510-514.

41. Wright RJ, Sledge CB, Poss R, Ewald FC, Walsh ME, Lingard EA: Patientreported outcome and survivorship after Kinemax total knee arthroplasty. J Bone Joint Surg Am 2004, 86-A(11):2464-2470.

42. Ma Y, Balasubramanian R, Pagoto SL, Schneider KL, Hebert JR, Phillips LS, Goveas JS, Culver AL, Olendzki BC, Beck J, Olendzki BC, Beck J, Smoller JW, Sepavich DM, Ockene JK, Uebelacker L, Zorn M, Liu S: Relations of Depressive Symptoms and Antidepressant Use to Body Mass Index and Selected Biomarkers for Diabetes and Cardiovascular Disease. Am J Public Health 2013, 103(8):e34-e43.

43. Zhang X, Bullard KM, Cotch MF, Wilson MR, Rovner BW, McGwin G Jr, Owsley C, Barker L, Crews JE, Saaddine JB: Association between depression and functional vision loss in persons 20 years of age or older in the United States, NHANES 2005-2008. JAMA Ophthalmol 2013, 131(5):573-581.

44. Li C, Ford ES, Zhao G, Tsai J, Balluz LS: A comparison of depression prevalence estimates measured by the Patient Health Questionnaire with two administration modes: computer-assisted telephone interviewing versus computer-assisted personal interviewing. Int J Public Health 2012, 57(1):225-233

doi:10.1186/1471-2474-15-440

Cite this article as: Singh and Lewallen: Are outcomes after total knee arthroplasty worsening over time? A time-trends study of activity limitation and pain outcomes. BMC Musculoskeletal Disorders 2014 15:440.

\section{Submit your next manuscript to BioMed Central and take full advantage of:}

- Convenient online submission

- Thorough peer review

- No space constraints or color figure charges

- Immediate publication on acceptance

- Inclusion in PubMed, CAS, Scopus and Google Scholar

- Research which is freely available for redistribution 